NBER WORKING PAPER SERIES

\title{
GEOGRAPHY AND THE INTERNET: \\ IS THE INTERNET A SUBSTITUTE OR A COMPLEMENT FOR CITIES?
}

\author{
Todd Sinai \\ Joel Waldfogel \\ Working Paper 10028 \\ http://www.nber.org/papers/w10028
}

\author{
NATIONAL BUREAU OF ECONOMIC RESEARCH \\ 1050 Massachusetts Avenue \\ Cambridge, MA 02138 \\ October 2003
}

We are grateful to the Wharton e-Business Initiative (WeBI) for giving us access to, and technical assistance with, the Media Metrix data. We received useful comments from seminar participants at Wharton, the University of Illinois, Duke, the Federal Reserve Banks of New York and Philadelphia, and the 2002 AEA Meetings in Atlanta. Sinai received financial support from the Ballard Scholars Program at the Zell-Lurie Real Estate Center, and Waldfogel thanks WeBI. Sam Chandan and Dan Simundza provided excellent research assistance. The views expressed herein are those of the authors and are not necessarily those of the National Bureau of Economic Research.

(C2003 by Todd Sinai and Joel Waldfogel. All rights reserved. Short sections of text, not to exceed two paragraphs, may be quoted without explicit permission provided that full credit, including (C) notice, is given to the source. 
Geography and the Internet: Is the Internet a Substitute or a Complement for Cities?

Todd Sinai and Joel Waldfogel

NBER Working Paper No. 10028

October 2003

JEL No. R00, R12, L81, L82

\section{$\underline{\text { ABSTRACT }}$}

We study the tendency to connect to the Internet, and the online and offline shopping behavior of connected persons, to draw inferences about whether the Internet is a substitute or a complement for cities. We document that larger markets have more locally-targeted online content and that individuals are more likely to connect in markets with more local online content, suggesting the Internet is a complement to cities. Yet, holding local online content constant, people are less likely to connect in larger markets, indicating that the Internet is also a substitute for cities. We also find that individuals connect to overcome local isolation: notwithstanding a large digital divide, blacks are more likely to connect, relative to whites, when they comprise a smaller fraction of local population, making the Internet a substitute for agglomeration of preference minorities within cities. Finally, using online and offline spending data, we find that connected persons spend more on books and clothing online, relative to their offline spending, if they are farther from offline stores. This indicates that the Internet functions as a substitute for proximity to retail outlets.

Todd Sinai

The Wharton School

University of Pennsylvania

308 Lauder-Fischer Hall

256 South 37 th Street

Philadelphia, PA 19104-6330

and NBER

sinai@wharton.upenn.edu

Joel Waldfogel

Public Policy and Management

The Wharton School

University of Pennsylvania

3100 Steinberg Hall-Dietrich Hall

Philadelphia, PA 19104-6372

and NBER

waldfogj@wharton.upenn.edu 
Traditionally, markets for news and information as well as some retail goods have been predominantly local. As a result, consumers' welfare has been limited by the size of their local market, and agglomeration of persons sharing similar preferences has improved their welfare by facilitating the provision of products they want. ${ }^{1}$ By agglomerating persons around the country indeed, around the world - into a single market, the Internet offers the potential to radically alter consumption possibilities. In particular, the Internet may serve as a substitute for urban agglomeration by leveling the consumption playing field between large, variety-laden and small, variety-starved markets. But this is not necessary. Leveling the field requires that content on the Internet be similarly attractive to persons in large and small markets. If the Internet offers local, as well as general, information, then its role as a substitute for agglomeration will be undermined. Indeed, if local online content is sufficiently attractive - and if it is more prevalent in larger markets - then the Internet may be a complement for urban agglomeration. ${ }^{2}$

In this paper we use information on how Internet connection tendencies, and connected persons' online and offline retail spending, are related to the attractiveness of their online and offline options to draw inferences about whether the Internet serves as a substitute or a complement for urban agglomeration. First, we examine the relationship between market size and available locally-targeted online content. To this end we characterize the nature of available content using Media Metrix data on 16.5 million web page visits by about 32,000 households in 326 Metropolitan Statistical Areas [MSAs] in August 2000. We document that substantially more

\footnotetext{
${ }^{1}$ We are aware of other arguments for agglomeration besides consumption. Henderson (1974) presents a model in which city size balances production benefits against congestion costs. See, for example, Ciccone and Hall (1996) or Rosenthal and Strange (forthcoming) for recent empirical evidence on the production benefits of agglomeration as well as additional references. There is little research on consumption benefits of agglomeration. Glaeser, Kolko, and Saiz (2001) is an exception.

${ }^{2}$ We are not the only authors to pose this question. See Kolko (1999), as well as Gaspar and Glaeser (1998), who find that telephones complement agglomeration because phone conversation complements face-to-face (two-way) communication. Our focus in this paper is on one-way communication over the web rather than two-way communication, but our question is similar. Finally, Forman, Goldfarb, and Greenstein (2003) examine a related question, the effect of urban location on diffusion of Internet technologies.
} 
online local content is available in larger markets, suggesting that Internet use may complement urban agglomeration.

We then examine how the tendency to connect to the Internet varies with metro area population - a proxy for available product variety - and locally targeted online content. Combining the Current Population Survey's August 2000 Computer and Internet Use module with our Media Metrix-derived data on local online content and Census data on local market size (as a proxy for offline product variety), we document that local online content attracts people to connect. When we separately account for both local online content and our measure of local offline variety (population), we find statistically significant direct evidence of both complementarity and substitutability. Individuals are more likely to connect in markets with more local online content, and holding local online content constant, are less likely to connect in larger markets. On balance we find that these effects offset each other so that the Internet neither promotes nor discourages agglomeration in larger markets.

Second, we shed light on the Internet's substitution for offline variety by examining the relationship between the tendency to connect and individuals' local isolation from persons sharing their preferences. The problem of dissatisfaction with offline options can be particularly acute for persons either isolated from products generally or with preferences unlike their neighbors'. It is clear from existing research that blacks and whites have sharply different preference in media products. As a result, the local availability of products that blacks value may have been limited not simply by the absolute size of their local markets, but also by the size of the local community sharing their preferences. ${ }^{3}$ If isolated blacks are more likely than blacks living among large

\footnotetext{
${ }^{3}$ For example, larger markets have more and better local newspapers (George and Waldfogel, 2003), radio broadcasts (Waldfogel, forthcoming), and television stations (Waldfogel, 2001). These studies document that black and white consumers' welfare, in their capacity as media consumers, increase in the size of their own respective group populations.
} 
concentrations of blacks to connect to the Internet, then we can infer not only that the Internet is a substitute for cities but also that it is a substitute for "product ghettoes," or groups of people within a market sharing in common their locally atypical product preferences. Again using the CPS data, we find that blacks are more likely to connect, relative to whites, as blacks have smaller local population, suggesting that the Internet is a substitute for "product ghettoes."

Finally, we examine effects of isolation measured by distance to retail establishments among a sample of Internet-connected respondents to the Wharton Virtual Test Market (WVTM) survey. Using 1997 Economic Census data on the location and size of book, music, and clothing stores, matched by zip code to data on WVTM respondents' online, catalog, and offline spending in each of those categories, we document that people buy more books and clothing online or via catalogs, relative to their offline expenditure in local stores, as they live farther from their nearest book and clothing store, respectively. This evidence shows that, at least in some categories, consumers use the Internet as a substitute for proximity to retail stores.

Friedman (1962) has argued that each person gets what she wants through market allocation, so that markets avoid the tyranny of the majority endemic to collective choice. Friedman's argument holds literally only when production can take place at arbitrarily small scale, so that available product variety does not depend on the size, or the preference composition of potential customers in the market. When fixed costs are sizable, the number of available products, and the resultant welfare of consumers in local markets can depend on the size and composition of the local market. By agglomerating consumers into larger markets, the Internet allows locally isolated persons to benefit from the product variety made available for consumers elsewhere. By increasing the size of markets relative to fixed costs, the Internet may therefore bring market 
allocation nearer to the ideal in which an individual's welfare does not depend on either the number of her neighbors or their product preferences.

The paper proceeds in six sections. Section 1 reviews available evidence on product variety and market size and characterizes the decision to use the Internet, as a function of one's preference type and the quality of local options. Section 2 describes the Current Population Survey (CPS), Media Metrix (MM), WVTM, and Economic Census data used in this study. Section 3 employs the MM data to quantify local content on the Internet and, in particular, to characterize how the availability of local content varies with market size. Section 4 employs the CPS data to characterize the demand for Internet connection. Section 5 examines how the balance of online and offline retail spending varies with connected consumers' distance to retail establishments. A brief conclusion follows.

\section{How Does the Internet Function as a Substitute or Complement for Cities?}

\section{The Internet as a Substitute for Cities}

When production entails fixed costs and preferences differ across individuals, the number of differentiated product options available locally will increase in the size of the market. ${ }^{4}$ Larger markets have more local product variety than small markets, and this greater variety draws a higher fraction of persons to consumption of local offline products. In this way persons benefit each other through what has elsewhere been termed a "preference externality" (Waldfogel, forthcoming).

By aggregating people in disparate locations into a single market, the Internet has the capacity to increase market size relative to fixed costs. ${ }^{5}$ This can, in turn, raise the number of

\footnotetext{
${ }^{4}$ This is an example of what Spence $(1976 a, b)$ terms the "product selection problem." See also Dixit and Stiglitz (1977).

${ }^{5}$ Computer technology may also reduce the absolute size of at least the exogenous component of the fixed and sunk costs of operating a busines s. Given the large advertising expenditures of web retailers such as Amazon.com, it is not
} 
available products and reduce the dependence of consumption options on the number and mix of consumers in one's local market. That is, consumers in small offline markets can instead turn to the Internet for products unavailable offline locally. What sorts of sites make the Internet a substitute for cities? Retail sites provide one clear possibility: a person who has no store nearby can instead buy online. We also have in mind sites that offer content that is not geographically specific but which may have greater appeal in smaller markets with less offline product variety. For example, Spinner.com offers 140 channels of streaming music programming, over twice the number of radio stations available in any of the largest US markets. Spinner.com may appeal to listeners in both large and small markets but is presumably provides more of a benefit to listeners in small markets with few traditional radio stations. News sites, such as CNN.com or MSNBC.com, present domestic and international news of interest to individuals in cities of all sizes. But because small markets tend to have slender local newspapers, people who live in them may place a higher value on the availability of news on the Internet.

\section{The Internet as a Substitute for Product Ghettoes}

The paucity of offline product variety is not determined solely by the total population in an area. To the extent that preferences differ across types of individuals, the number of like-minded persons in a local area will determine the size of the offline market and the amount of locally available offline products that would appeal to those people. Since the distribution of types differs across geographic markets, we expect persons to be more likely to connect to the Internet to satisfy their locally unfulfilled tastes when they are "preference minorities," that is, part of a group with distinct preferences that makes up a small number of the local population. For example, it is well

clear whether web businesses have lower fixed costs than bricks and mortar businesses, when endogenous fixed costs are taken into account. See Sutton (1991) for extensive discussion of endogenous fixed costs. 
documented that blacks and whites have sharply different preferences in some categories of products. In particular, the radio programming formats attracting two thirds of black listening collectively attract less than 2 percent of nonblack listening. In major cities with both tabloid and non-tabloid newspaper options, the tabloid attracts about three quarters of black readers, compared with about a third of nonblack readers.

\section{The Internet as a Complement for Cities}

In addition to providing universal content that appeals to individuals in any size market, the Internet may also be a local medium. The Internet can provide information that helps people to navigate cities, and may deliver other goods and services that improve city life. For example, city portals, such as boston.citysearch.com, provide information about events, restaurants, and movie listings. Match-making sites, such as boston.matchmaker.com, help users in large cities meet each other. And sites associated with local newspapers or television stations provide another distribution channel for local news. If there are fixed costs associated with producing such content, then the number and variety of local sites may increase in the size of the local market, making the Internet more useful to people in larger markets and mitigating the Internet's role as a substitute for local offline product variety.

Just as Internet access can complement cities generally, web retailers can complement proximity to offline retailers. Many web retailers, such as gap.com, allow items purchased online to be returned or exchanged at their offline stores. ${ }^{6}$

\footnotetext{
${ }^{6}$ According to the Gap: "All online merchandise can be returned to any U.S. Gap store or by mail. Make sure to choose the "gift receipt" option at checkout if you're sending the gift directly to the recipient." (according to http://www.gap.com/asp/home gap.html?wdid=0, accessed September 17, 2003).
} 
These considerations motivate the four questions that this study addresses. How much web content is local? Is there more local online content in larger markets? How does the tendency to connect - and uses of the Internet - vary with one's local offline and online options?

\section{Data}

Data for this study are drawn from four sources, the August 2000 Current Population Survey Computer and Internet Use Supplement, an August 2000 Media Metrix data extract, the Wharton Virtual Test Market (WVTM), and the 1997 Economic Census. The CPS supplement has information on Internet connection, as well as demographic and geographic information, for roughly 50,000 households in August 2000. We reduce our sample to 29,027 by restricting our attention to those households that live in metropolitan statistical areas (MSAs) that can be matched to MSAs in our Media Metrix data set.

The first column of Table 1 reports sample characteristics. Because we are interested in factors that may affect the likelihood of a household using the Internet, we first define a household as Internet connected if the household reports Internet access from home. Almost 44 percent of the households in our sample have such connections. Just over half the sample has one or more computers at home. Of the household heads in the sample, more than 13 percent are black, and 30 percent are at least college-educated.

The household heads in the portion of the sample that is Internet-connected is disproportionately white and is more highly educated than the population as a whole. ${ }^{7}$ Only about 7 percent of the connected sample is black-headed, and approximately 45 percent of the households

\footnotetext{
${ }^{7}$ These results are consistent with evidence elsewhere on the digital divide. See http://www.ntia.doc.gov/ntiahome/fttn99/contents.html .
} 
are headed by a college-educated person. Naturally, nearly all of the connected sample of households has a home computer.

Our second data source follows the Internet usage behavior of a panel of households. Media Metrix collects data on all web page visits by a representative sample of households in 326 MSAs by placing recording software on panelists' computers. In our extract, which covers August 2000, each visit to a web page, or page "hit," by a household is a separate record - with 16.5 million page visits in total during the month. ${ }^{8}$ Media Metrix appends basic information about their Internet-connected panelists, such as MSA, income category, educational attainment, and race, to their data on web surfing. The third column of table 1 reports the education distribution for the Media Metrix sample, and it is similar to the CPS sample of households with Internet connections at home (in column 2). The Media Metrix sample is a little more highly educated than the CPS sample, but that result is generated in part by our applying the highest level of educational attainment of any member in the household to the whole household.

In addition, for each site visit, we observe the URL, or "address" of the web page, which Media Metrix classifies into one of 27 categories. ${ }^{9}$ The first column of table 2 reports the distribution across these categories of page hits and numbers of visited sites. ${ }^{10}$ The category with the most hits is portals, with 21.9 percent of the total hits, followed by services (15.9), entertainment (12.5), adult content (8.0), retail (5.4) and auctions (4.3). Business-to-business sites have the fewest hits by our sample of residential households with only 0.1 percent of the total. Turning to the number of unique sites visited in each category, reported in column 3, "adult

\footnotetext{
${ }^{8}$ A "site," in our extract, is typically a three-level name, such as www.aol.com The data contain other sites at America On-line (AOL), such as members.aol.com, as separate "sites," even though they are in the same "domain." ${ }^{9}$ The Media Metrix categories are: Auctions, Automotive, Business/Finance, Careers, Community, Corporate Presence, Directories/Resources, Education, Entertainment, Government, Health, Hobbies, Lifestyle, News/Information, Portals, Real Estate, Regional/Local, Retail, Search/Navigation, Sports, Technology, Travel, Services, Adult Content, Business to Business, All Other, and Religion.

${ }^{10}$ In order to be included in the total hits or sites calculations, a site must be estimated to have received at least 5,000 hits during the month.
} 
content" has the largest share of sites with 23.0 percent of the 22,432 total sites the Media Metrix panelists visited. However, the portals category, which received a large portion of the total number of page hits, comprises a very small fraction of the sites in the sample, just 1.0 percent. This pattern indicates that there is more concentration in the portals, with a few sites each receiving a large amount of traffic. We return to the latter part of table 2, on local sites, later in the paper.

The third data source is the WVTM, which is an internet-based survey of more than 20,000 Internet users. For this project, we used data from the third and fourth waves, which were collected during 1999 and 2000, respectively. The WVTM is designed to be representative, but is not random. Survey participants were recruited by banner advertisements. The ad placements were targeted to recruit a demographically representative population. This survey is well suited for our purposes since it breaks down how much money the respondent spent over the last two months via Internet sites, catalogs, and physical stores on books, music, and clothing. The WVTM also records the respondent's zip code, which enables us to match the spending data to geographical characteristics. In addition, the survey records a host of demographic information, including gender, race, income, and education. The fourth column of table 1 shows demographic characteristics of the individuals in the WVTM sample. The education and race distributions are at least broadly similar across connected samples.

The fourth and final data source in the study is the 1997 Economic Census, one wave of a census of business establishments that is collected every five years by the Bureau of Census. For 1997, the Census department surveyed more than 5 million establishments with employees and collected administrative data on 15.5 million additional small establishments. For each establishment, which is a physical location providing a service or making or distributing goods, Census recorded its location, industry, dollar volume of sales, number of employees, and payroll. 
For each line of business (NAICS code) and zipcode, the Census reports the number of stores in each of the following size classes, by thousands of dollars of annual retail sales: 0-100, 100-200, 200-500, 500-1000, and over 1 million. In this study we are interested in books (NAICS code 451211), music (NAICS code 45122), and clothing stores (NAICS code 4481). ${ }^{11}$ Matching the zipcodes of the WVTM respondents to the zipcode distribution of stores, we can calculate the numbers of book, music, and clothing stores within any distance for each individual in the sample. ${ }^{12}$ Table 3 describes some of these data. For example, the first entry in the first column indicates that persons in the sample have an average of 1.37 bookstores within a one-mile radius. If we restrict attention to large bookstores (with over $\$ 1$ million in annual sales), the number is 0.47 bookstores. Music stores are slightly less proximate than bookstores - an average person has 1 within a mile, while clothing stores are much more dense: the average is nearly 10 within a mile.

\section{How Much Content is Local?}

To determine whether the Internet is a complement to cities, we need to measure the amount of local content targeted at each metropolitan area. As our metric, we count the number of sites that produce content that appeals primarily to one particular market. Unfortunately, there exists no comprehensive list of sites by locale from which one could characterize local content. ${ }^{13}$ Indeed, one cannot determine the localness of a site's targeting from the registration location of a site, or where the parent company's headquarters are located, since the site's visitors could be from anywhere.

\footnotetext{
${ }^{11}$ We experimented with alternate definitions: including department stores, superstores, and electronics stores in music, and including department and superstores with clothing. In all cases, results were very similar to those reported.

${ }^{12}$ Distance is measured between the centroids of the two zip codes.

${ }^{13}$ Kolko (1999) uses the list of registered domain names and shows higher "domain density" in larger markets, which is at least suggestive that web content is complementary with cities. Domain registration indicates the geographic location of the registrant, not the site users, however.
} 
Fortunately, we can use the Media Metrix data to measure the geographic focus of a site. By recognizing that a locally targeted site must have a primarily local audience, we can use the geographic origin of a site's visitors as reported in the Media Metrix data to estimate the extent of its local focus and which market it primarily serves. In essence, after calculating every site's share of each market's total page hits, we presume that a site that has a sufficiently high proportion of its total market shares across all markets coming from just one market must be providing content of local interest to that market.

To make this more concrete, we compute each site's index of "site localness" as $1 / \sum_{j}\left[\frac{p_{i j} / H H_{j}}{\sum_{j}\left(p_{i j} / H H_{j}\right)}\right]$, where $p_{i j}$ is page visits to site $i$ from MSA $j$ and $H H_{j}$ is the number of households in MSA $j$. This formula is essentially an inverse HHI scaled to reflect the fact that population varies across MSAs. If we did not normalize by each MSA's total households, sites would appear to be targeted towards larger MSAs even if they truly were equally appealing to any individual in any part of the country. When all visitors are from a single MSA, the index is 1 . If a site has equal average hits per household in two MSAs, the index is 2. The larger the index, the less local a site. A perfectly geographically neutral site's index equals the number of MSAs in the sample. We define a site as local if it has a "localness index" of two or less, and we attribute the site to the locale that contributes the site's largest market share. ${ }^{14}$

Because our measure of localness depends on the composition of a site's audience, our accuracy in classifying sites as local diminishes for sites with very few visits from the Media Metrix panel during the month. To counteract that problem, we require that sites exhibit a

\footnotetext{
${ }^{14}$ The most obvious type of local site that we misclassify as not local are sites which contain local information for a number of locales. Since we require that a site be targeted to one locale to be defined as local, these sites do not qualify. However, we suspect the narrowly targeted sites are a reasonable proxy for the localness patterns we would find if we used a more broad definition.
} 
minimum level of interest, as measured by page hits, in the MSA that they target in order to be considered local to that market. Since Media Metrix does not sample proportionally to market population, we estimate the actual number of hits by multiplying the number of hits per household in Media Metrix by the number of connected households in the MSA, as calculated from the CPS. A cutoff of 5,000 hits is applied to the resulting estimate. This way, even if one city has fewer households than another in the Media Metrix panel, our threshold maintains the same economic importance across locations. We also exclude MSAs with fewer than 20 Media Metrix households from these calculations in order to reduce the error in measuring hits per household. That leaves us with 113 MSAs that we are able to match to the CPS data.

When we look at the sites with the largest and smallest adjusted localness indices across Media Metrix categories, the index produces reasonable results. The least local sites have localness indices over 20 and include such familiar sites as CBS.com (entertainment), microsoft.com (corporate presence), ebay.com (auctions), autobytel.com (automotive), theglobe.com (communities), SSA.gov (government), MSNBC.com (news/information), netscape.com (portals), buy.com (retail), jobsonline.com (careers), google.com (search/navigation), and SmarterLiving.com (travel). ${ }^{15}$

The most local sites have localness indices close to one and tend to refer to locales in their URL. For example, siliconalleyjobs.com (careers), state.de.us (government), ncweb.com (communities), baltimoresun.com (news/information), sanantonio360.com (portal), corealty.com (real estate), searchchicago.com (regional/local), and uscfootball (sports) all have localness indices equal to one meaning that all their hits came from one MSA. Many other local sites are associated with local newspapers or television stations.

\footnotetext{
${ }^{15}$ We have suppressed the "www" site name prefix for clarity.
} 
Columns (5)-(10) of table 2 show the distributions of hits to local sites, and local sites themselves, across Media Metrix categories. On average, 5.3 percent of all hits are to the 7,273 sites that we deem local. In column 7, more than a third of the hits to sites in the education and regional/local categories are deemed local. Nearly half of the news/information sites are local, as reported in the last column, though they account for just 15 percent of the category's hits. Auctions has the lowest share of its hits considered to be local, followed by portals. Travel and automotive have the lowest rate of its sites being local.

The average number of local sites per MSA, reported in table 4, follows the same general pattern. There is an average of 64 local sites in each MSA, with a maximum of 841 local sites in the New York-Northern New Jersey-Long Island, NY-NJ-CT-PA CMSA. The largest individual categories are Adult Content and Entertainment.

We finish our description of the local site data by asking how the amount of local content varies with the size of the local market. If there are fixed costs of providing a local online site, then the quantity of local online content will increase in the size of the local connected market. And, in turn, the heightened content availability in larger markets will reinforce the Internet as a complement for cities. In traditional media, as we have mentioned above, larger markets have more local content (more radio stations, more and better local newspapers, more television stations). Are there similarly more local online sites in larger markets? ${ }^{16}$

Table 5 reports regressions of MSA local online content, overall and by the larger categories, on total MSA population. An additional million residents in an MSA adds 48 total local sites. The relationship between MSA population and the number of local sites is positive and significant for all of the larger Media Metrix categories. That larger markets have more Internet

\footnotetext{
${ }^{16}$ The empirical question addressed in this section mirrors the question of the entry literature: how does the number of firms (or products) vary with market size. See Bresnahan and Reiss (1991), for example.
} 
content indicates that the Internet is not simply a leveler of utility across geography and, indeed, may be a city complement. As in local media, the extent of online content increases in the size of the market.

\section{The Demand for Internet Connection}

This section examines how the tendency to connect to the Internet varies with measures of the extent of local online and offline options. ${ }^{17}$ Our basic measures of the extent of offline options are total local population, which is presumed to increase the variety of goods and services available. In our second approach, a resident's relevant product variety is determined by the size of the market of people who share her preferences. In our estimation, we will measure that market with the population - and population share - of one's group, where the groups are blacks and nonblacks.

Our measure of local online product variety is the number of local sites. Although table 5 shows that the Internet provides more local content in bigger places, it does not say whether the Internet actually enhances city life. For that to be true, people must want local content. There is ample evidence in traditional local media that the greater variety brought forth in larger markets attracts a higher fraction of the population to consumption. The radio listening, television viewing, and newspaper reading shares are higher in larger markets. The greater quality and variety of options in traditional media provide a reason why persons' welfare, in their capacity as media consumers, may be higher in larger markets. What about Internet use? Does the greater variety of

\footnotetext{
${ }^{17}$ One might in principle study demand for Internet connection as a function of price or availability of ISPs. Greenstein (1999) indicates that by 1998 Internet access is widely available in all MSAs. The price of Internet access also varies little across MSAs. A regression of the 1998 CPS measure of monthly ISP costs (hesiu9) on 1990 MSA population gives a constant of $\$ 17.46$ (s.e. $=\$ 0.21$ ) and a population coefficient indicating that the price paid for access increases by $\$ 0.043(\$ 0.018)$ per million of additional population.
} 
online options targeted at big-city consumers attract a higher fraction of them to the Internet? If so, then the Internet functions as a city complement.

\section{Internet Connection and the Extent of Local Offline and Online Options}

We examine how the tendency to connect is affected by local offline variety by using the CPS data to estimate probits of an individual having a home Internet connection as a function of MSA population or its log:

$$
C_{i}=\alpha+\beta \cdot P O P_{m}+\delta \cdot X_{i}+\varepsilon_{i m}
$$

The left-hand-side variable, $C$, takes the value of one if household $i$ has an Internet connection at home. Our basic measure of local offline product availability, MSA population, is denoted by $P O P$ and varies only at the MSA level, $m$. In some specifications, we add a large set of household level demographic controls, $X_{i}$, including race of head, gender, household head education and age dummies, and the number of children in the household. In those specifications, the estimated coefficient on POP will measure the effect of offline variety in the local market on households' decisions to connect to the Internet even after accounting for their own characteristics.

The first and fifth columns of table 6 , which include only population or its log as a measure of market size, show that overall the probability of connecting to the Internet does not vary with market size. The point estimate in the level specification (5) is slightly negative but indistinguishable from zero, and the log estimate is positive and insignificant. ${ }^{18}$ By itself the absence of a relationship between market size and connection indicates that substitution and complementarity effects of the Internet are either nonexistent or offsetting. Supplementing these

\footnotetext{
${ }^{18}$ The standard errors in all of these and subsequent regressions are adjusted for clustering by MSA.
} 
specifications with individuat level controls for education, age, and presence of children in columns (3) and (7) has little substantive effect. The market size coefficients remain insignificant.

We distinguish the substitute and complement effects by adding a measure of the number of local online options. Columns (2) and (6) add the total number of local sites $\left(L O C A L_{m}\right)$ (or its $\log$ ) in the MSA to the specifications in columns (1) and (5), resulting in the following equation:

$$
C_{i}=\alpha+\beta \cdot P O P_{m}+\gamma \cdot L O C A L_{m}+\delta \cdot X_{i}+\varepsilon_{i m}
$$

In this regression, $\beta$ measures the sensitivity of connection to offline options (as measured by market size), and $\gamma$ reflects the sensitivity of connection to local online content. In the log specification without controls (column 2) the coefficient on local population is negative and significant, and the coefficient on local sites is positive and significant. Results in levels are similar, although less significant. Finally, columns (4) and (8) include controls and show the same pattern (negative coefficient on market size, positive coefficient on local sites) but are not statistically significant in conventional two-sided tests. While statistical significance levels are not high, the results suggest that local content attracts households to connect to the Internet but that households in larger markets are otherwise less likely to connect.

The patterns of results in table 6 are noteworthy. First, the absence of a relationship between connection tendency and market size stands in clear contrast to the city-complementing relationships documented for traditional local media (radio, television, and daily newspapers). Second, when both market size and local sites are included in the estimation, there is some evidence that the lack of overall effect is due to distinct and offsetting substitute and complement effects of the Internet on agglomeration. The results at least suggest that local content, which is more plentiful in larger markets, attracts people to the Internet. Holding constant the amount of local online content, people are less likely to connect as their local offline options, proxied by 
population, are more appealing. The Internet functions as both as a substitute and a complement for cities.

\section{Internet Connection and Racial Isolation}

While the Internet does not function, on balance, as a substitute for cities generally, it may still allow locally isolated households to surmount the limitations of their local offline markets. To put this another way, the Internet may be a substitute for "product ghettoes." To investigate this we ask whether racially isolated individuals are more likely to connect to the Internet. We implement this in table 7 by asking whether blacks (nonblacks) are less (more) likely to connect as blacks face less appealing local offline product options.

Depending on the nature of local products, their appeal to blacks might reflect either the proportion or absolute number of blacks in the local area. For products with large fixed costs relative to market size, a local market supplies few options, and positioning relative to black preferences depends on the fraction black in the local market. ${ }^{19}$ For products with smaller fixed costs relative to market size, a local market can supply multiple options, and the appeal of the local offline product options depends on the absolute number of blacks. ${ }^{20}$ Because the local alternatives to content offered over the Internet may take either form, we perform tests of whether blacks use the Internet to overcome racial isolation using both absolute levels of black population and percentages.

First, we perform the test in levels, running probits of the connection dummy on the MSA populations of blacks and nonblacks. We also run the test in percentages, substituting the black

\footnotetext{
${ }^{19}$ George and Waldfogel (2003) document this as the mechanism for local daily newspapers. The appeal of the few daily papers in a market depends on the fraction black in the market. Similarly, Waldfogel (2001) documents that the absolute amount of black-targeted local televis ion programming varies with the fraction black in the market.

${ }^{20}$ Waldfogel (forthcoming) documents that the number of black-targeted radio stations, as well as the black tendency to listen to the radio, vary with the size of the local black population.
} 
share for the market populations. Columns (1) and (2), and (5) and (6), of table 7 report separate black and nonblack regressions of the tendency to connect on either the absolute numbers of blacks and nonblacks or the fraction black in the MSA. All of the specifications in table 7 include the full set of individual-level controls. As columns (1) and (2) show, while the nonblack connection tendency does not vary significantly with black or nonblack population, the black connection tendency decreases in black population and increases in nonblack population. The relationships of interest in column (2) are statistically significant or nearly so. Columns (5) and (6) perform the tests in percentages. The nonblack tendency to connect is invariant with the percent black in the MSA, while the black connection tendency is (almost significantly) smaller in MSAs with larger black shares.

It is possible, however, that local market-level unobserved factors, such as local offline traffic congestion or the quality of local offline media products, affect the tendency for persons in that market to connect to the Internet. We can accommodate this by including a local market fixed effect. When we do this, we cannot identify effects of market-level factors, such as group population, or the percent black in the market. We can, however, identify the difference between the effect of the MSA's populations of blacks and nonblacks (or the MSA black share) on black and white tendencies to connect via a coefficient on a black dummy interacted with, say, the MSA percent black.

Columns (3) and (4) of table 6 report estimates of the MSA fixed effects specifications, both probits and linear probability models, in absolute population levels; and the results are significant in the anticipated direction. Markets with more blacks have a lower tendency for blacks to connect to the Internet, relative to the nonblack tendency to connect; and markets with more nonblacks have a higher tendency for blacks to connect. Columns (7) and (8) report analogous 
MSA FE specifications in percentages. They show a negative, although not significant, coefficient on the interaction of the black dummy with the black population share (the coefficients are over 1.5 times their standard errors). These results provide evidence that persons are more likely to connect, the more they are isolated locally, or that the Internet is a substitute for product ghettoes.

\section{The Ironic Digital Divide?}

Evidence above indicates that blacks are more likely to connect as they are more isolated. Blacks make up about 15 percent of the population in sample MSAs and so are in some sense isolated in most places. If people connect to avoid isolation and blacks are isolated, blacks should be more likely than whites to connect. Yet, the large and significant negative coefficients on the black dummy in columns (3), (4), (7), and (8) confirm the existence of the digital divide. ${ }^{21}$ We can offer two explanations for this puzzle. First, ample evidence indicates that blacks have sha rply different content preferences in other media. Even if there were no digital divide, the black Internet audience would be much smaller than the white one. Consequently there would be less absolute content of interest to blacks, giving rise to a smaller black connection tendency.

Second, we have documented that local content attracts people to connect. Because our MM sample contains too few blacks per locale, our data do not allow us to quantify local grouptargeted content. Still, it is safe to assume that there is little black-targeted local content on the Internet that would attract connection.

\section{Retail Spending and Isolation from Retail Stores}

\footnotetext{
${ }^{21}$ See Fairlie (2002) for comprehensive documentation that blacks are less likely than whites to be connected to the Internet, after accounting for a host of observable variables.
} 
We now turn to our final test for substitution, based on retail spending. The WVTM data allow us to ask whether individuals overcome isolation, in this case from nearby retail establishments, by making purchases on the Internet. For each individual in the WVTM sample, we have data on purchases of three types of merchandise (books, music, and clothing) via two channels, offline stores and online (which we define as Internet and catalog). Thus, for each individual (i) we observe 6 spending variables. In addition, we know each individual's zipcode location, and from the Economic Census we know the size distribution of retail stores in each merchandise category by zipcode. As a result we can calculate the number of stores in given radii from each individual in the sample.

Table 8 examines online ${ }^{22}$ and offline spending on books, music, and clothing, by proximity to offline stores in the category. For example, persons living within a mile of a bookstore spend an average of $\$ 99$ per year at bookstores, about 46 percent of it online. As distance from bookstores increases, total spending on books declines, presumably reflecting lower tastes for books by people who live in isolated places. Individuals over 20 miles from a bookstore spend an average of $\$ 68$, but the fraction spent online is nearly 53 percent. Finally, total spending on music also declines with distance to stores. Except for those most distant from music stores, the fraction spent online increases with distance from music stores.

Clothing accounts for more spending, and a higher fraction - about two thirds - is offline. The online fraction increases from 35 to 38 percent as distance from clothing stores increases, although the increase is not monotonic. Individuals whose nearest store is 1-2 miles away spend the highest fraction (nearly 41 percent) online.

While table 8 provides suggestive evidence that people use the Internet to overcome isolation from retail establishments, there are stronger tests available with these data, to which we

\footnotetext{
22 “Online" here means online and catalog.
} 
now turn. Table 9 documents this via regressions of category spending on a measure of distance to the nearest category store, with and without controls (dummy variables for household income and education level). ${ }^{23}$ Each coefficient in the table is from a separate regression. The first two columns, for example, show how online and offline book spending vary across persons by their distance from an offline store. Both online and offline spending decline with distance, although offline spending declines more sharply, particularly for books and clothing.

In the specifications without controls, both online and offline spending are smaller for individuals living farther from stores. When controls are included, offline spending does not decline significantly with distance for books or clothing, although it does for music. Importantly, though, the online decline with dis tance is sharper (for books and clothing). To the extent that total spending varies with distance, we can infer that individuals' 'tastes for consumption' vary with distance. Thus the fact that offline spending declines in distance (in even-numbered columns of table 9) does not provide clean evidence for the theory.

We need a model that accommodates tastes for consumption that vary across individuals.

To this end we estimate a model with individual fixed effects:

$$
S_{i o}=\alpha_{0}+\alpha_{1} D_{i}+\alpha_{2} \delta_{I}+\alpha_{3} \delta_{I} D_{i}+\mu_{i}+\varepsilon_{i o}
$$

where

$S_{i o}$ is individual's spending on, say, books though outlet o (online or off),

$D_{i}$ is the individual's distance to a the nearest bookstore,

$\delta_{I}$ is a dummy for online, and

$\mu$ is an individual fixed effect (the taste for books, independent of channel).

\footnotetext{
${ }^{23}$ For these regressions we code distance as the top of the cell. For example, if one has a store in the 0 - 1 mile radius, we code distance as 1 mile. We code distance somewhat arbitrarily as 30 miles for persons without stores within 20 miles. We experimented with other values (40, 50, 100 miles) and found similar results.
} 
When this model is estimated with individual fixed effects, only $\alpha_{2}$ and $\alpha_{3}$ are estimable. The parameter $\alpha_{2}$ shows how much more people spend on books online than off. The parameter of interest $\alpha_{3}$ shows how spending-distance gradient varies online as opposed to offline. If $\alpha_{3}$ is positive, it indicates that, relative to offline spending, online spending rises with distance to the nearest store. $^{24}$

The three columns of table 10 run specification (1) on each of the merchandise categories, and the estimates of $\alpha_{3}$ are positive and significant for books and clothing (zero for music). These estimates indicate that after accounting for individuals' tendency to spend in a category, online spending increases in distance relative to their offline spending (in books and clothing). More succinctly, this indicates that for clothing and books at least, isolation from retail establishments induces Internet-connected persons to make relatively more purchases over the Internet.

\section{Conclusion}

It is apparent from our results that, in spite of more and better local online options in larger markets, the tendency to connect to the Internet is not affected by market size. This result stands in sharp contrast to relationships in traditional media, which reinforce the welfare advantages of la rger markets for consumption. In the case of the Internet, local content does encourage increased connection in larger markets, as with traditional media. However, unlike traditional local media, the Internet also provides access to a national level of variety for small places, mitigating the advantage of larger markets over smaller ones. This kind of effect is especially clear in blacks' tendency to use the Internet relative to whites to overcome preference isolation. In spite of black

\footnotetext{
${ }^{24}$ The individual-level controls are subsumed by the individual fixed effect.
} 
isolation and the tendency toward Internet use to overcome isolation, blacks remain relatively unlikely to use the Internet, possibly for lack of appealing Internet content.

The Internet holds out the promise of erasing differences in consumption opportunities arising from isolation, either from living in small markets or near small groups of preference compatriots. There is some evidence that the Internet accomplishes both of these functions. All else equal, the Internet is more attractive in small markets than in large ones. And online retail spending on books and clothing is higher, relative to offline spending in those categories, as people live farther from offline stores. Thus, there is evidence from a variety of results in the paper that the Internet functions for consumers as a substitute for agglomeration. Yet, all else is not equal. There is more local Internet content in larger markets, so the Internet is more attractive in larger places than in smaller ones. The complementarity of local sites with local agglomeration offsets the Internet's substitute function.

The Internet is a young technology whose diffusion is not complete. It is perhaps surprising that we find any relationship between connection tendencies and various kinds of isolation. It is probably too early to sensibly determine whether the Internet has fulfilled its promise, but it seems fair to observe, at this point, that the Internet has not yet rendered geography irrelevant. To paraphrase Mark Twain, reports of the death of cities at the hands of the Internet may be greatly exaggerated. 


\section{References}

Bresnahan, Timothy F; Reiss, Peter C. "Entry and Competition in Concentrated Markets." Journal of Political Economy. Vol. 99 (5). p 977-1009. October 1991.

Ciccone, Antonio and Robert E. Hall. "Productivity and the Density of Economic Activity." American Economic Review. Vol. 86 (1). p 54-70. March 1996.

Dixit, Avinash K; Stiglitz, Joseph E. "Monopolistic Competition and Optimum Product Diversity." American Economic Review. Vol. 67 (3). p 297-308. June 1977.

Fairlie, Robert. "Race and the Digital Divide." University of California at Santa Cruz. Mimeo. 2002. (available at http://econ.ucsc.edu/ fairlie/papers/digitaldivide7.pdf).

Forman, Chris, Avi Goldfarb, and Shane Greenstein. "How Did Location Affect Adoption of the Commercial Internet? Global Village, Urban Density, and Industrial Composition” NBER Working Paper 9979, September 2003

Friedman, Milton. Capitalism and Freedom. Chicago: University of Chicago Press, 1962.

Gaspar, Jess and Edward L. Glaeser. "Information Technology and the Future of Cities." Journal of Urban Economics. Vol. 43 (1). p 136-56. January 1998.

George, Lisa and Joel Waldfogel. "Who Affects Whom in Daily Newspaper Markets?” Journal of Political Economy. August 2003.

Glaeser, Edward L., Jed Kolko, and Albert Saiz. "Consumer City," Journal of Economic Geography 1 (2001): 27- 50.

Greenstein, Shane. "Building and Delivering the Virtual World: Commercializing Services for Internet Access." Mimeo. Kellogg School. 2000.

Henderson, J. V. "Optimum City Size: The External Diseconomy Question.” Journal of Political Economy. Vol. 82 (2). p 373-88. Part I, March-April 1974

Kolko, Jed. "The Death of Cities? The Death of Distance? Evidence from the Geography of Commercial Internet Usage.” Mimeo. Harvard University. 1999

Rosenthal, Stuart S. and William Strange, "Evidence on the Nature and Sources of Agglomeration Economies", prepared for the Handbook of Urban and Regional Economics, Volume 4, Elsevier, forthcoming.

Spence, Michael. "Product Selection, Fixed Costs, and Monopolistic Competition." The Review of Economic Studies. Vol. 43 (2). p 217-35. June 1976. 
Spence, Michael. "Product Differentiation and Welfare." American Economic Review. Vol. 66 (2). p 407-14. May 1976.

Sterngold, James. “A Racial Divide Widens on Network TV.” New York Times. December 29, 1998. P. A1.

Sterngold, James. "For All the TV Pilots, There's Just Not Enough Youth to Go Around." The New York Times, May 17, 1999. Page E1.

Sutton, John. Sunk costs and market structure: Price competition, advertising, and the evolution of concentration.. Cambridge, Mass. and London: MIT Press. 1991.

Waldfogel, Joel. "Preference Externalities: An Empirical Study of Who Benefits Whom in Differentiated Product Markets.” NBER paper 1999.

Waldfogel, Joel. "Preference Externalities: An Empirical Study of Who Benefits Whom in Differentiated Product Markets." forthcoming. RAND Journal of Economics.

Waldfogel, Joel. "Who Benefits Whom in Local Television Markets?" Mimeo. The Wharton School. November 2001. 


\section{Table 1: CPS and Media Metrix Sample Characteristics}

\begin{tabular}{|c|c|c|c|c|}
\hline & \multicolumn{2}{|c|}{ August 2000 CPS } & \multirow[t]{2}{*}{$\mathrm{MM}$} & \multirow[t]{2}{*}{ WVTM } \\
\hline & $\begin{array}{l}\text { all heads of } \\
\text { households }\end{array}$ & $\begin{array}{c}\text { connected } \\
\text { household } \\
\text { heads }\end{array}$ & & \\
\hline Internet at Home & 43.7 & 100.0 & 100.0 & 100.0 \\
\hline $\begin{array}{l}\text { Computer(s) at } \\
\text { Home }\end{array}$ & 54.3 & 98.8 & 100.0 & \\
\hline White & 82.2 & 87.3 & 88.7 & 85.1 \\
\hline Black & 13.4 & 7.4 & 4.5 & 3.4 \\
\hline Native American & 0.6 & 0.4 & N/A & 0.5 \\
\hline Asian & 3.8 & 4.9 & 3.0 & 5.6 \\
\hline Less than High & & & & \\
\hline School & 14.7 & 4.1 & 2.0 & 1.8 \\
\hline High School & 28.5 & 20.1 & 9.7 & 19.3 \\
\hline Some College & 26.7 & 30.3 & 27.0 & 43.4 \\
\hline College & 19.6 & 28.7 & 36.4 & 23.4 \\
\hline Post Graduate & 10.5 & 16.7 & 24.8 & 12.1 \\
\hline Observations & 29027 & 12685 & 17104 & 21309 \\
\hline
\end{tabular}

Note: CPS sample includes only households in MSAs that match with Media Metrix sample (and contain at least $20 \mathrm{MM}$ households). Media Metrix sample includes only households in MSAs. In both samples, included observations must have valid entries for age, education, and race of the household head. Media Metrix education is the maximum educational attainment of either spouse if the household is married. 
Table 2: Distribution of Hits and Sites, by Category

\begin{tabular}{|c|c|c|c|c|c|c|c|c|c|c|}
\hline \multirow[b]{2}{*}{ Category } & \multicolumn{4}{|c|}{ All Sites } & \multicolumn{6}{|c|}{ Local Sites } \\
\hline & Hits & $\begin{array}{l}\text { Pct of } \\
\text { Total }\end{array}$ & Sites & $\begin{array}{l}\text { Pct of } \\
\text { Total }\end{array}$ & Hits & $\begin{array}{l}\text { Pct of } \\
\text { Total }\end{array}$ & $\begin{array}{c}\text { Pct of } \\
\text { cat hits }\end{array}$ & Sites & $\begin{array}{l}\text { Pct of } \\
\text { Total }\end{array}$ & $\begin{array}{c}\text { Pct of } \\
\text { cat sites }\end{array}$ \\
\hline Auctions & 715,491 & $4.3 \%$ & 71 & $0.3 \%$ & 3,106 & $0.4 \%$ & $0.4 \%$ & 24 & $0.3 \%$ & $33.8 \%$ \\
\hline Automotive & 115,769 & $0.7 \%$ & 215 & $1.0 \%$ & 1,984 & $0.2 \%$ & $1.7 \%$ & 42 & $0.6 \%$ & $19.5 \%$ \\
\hline Business/Finance & 508,931 & $3.1 \%$ & 491 & $2.2 \%$ & 43,067 & $4.9 \%$ & $8.5 \%$ & 122 & $1.7 \%$ & $24.8 \%$ \\
\hline Careers & 144,138 & $0.9 \%$ & 130 & $0.6 \%$ & 1,086 & $0.1 \%$ & $0.8 \%$ & 49 & $0.7 \%$ & $37.7 \%$ \\
\hline Community & 338,323 & $2.1 \%$ & 324 & $1.4 \%$ & 29,845 & $3.4 \%$ & $8.8 \%$ & 137 & $1.9 \%$ & $42.3 \%$ \\
\hline Corporate Presence & 505,089 & $3.1 \%$ & 1,061 & $4.7 \%$ & 11,663 & $1.3 \%$ & $2.3 \%$ & 266 & $3.7 \%$ & $25.1 \%$ \\
\hline Directories/Resources & 417,353 & $2.5 \%$ & 1,258 & $5.6 \%$ & 43,754 & $5.0 \%$ & $10.5 \%$ & 462 & $6.4 \%$ & $36.7 \%$ \\
\hline Education & 234,527 & $1.4 \%$ & 628 & $2.8 \%$ & 87,553 & $10.0 \%$ & $37.3 \%$ & 206 & $2.8 \%$ & $32.8 \%$ \\
\hline Entertainment & $2,259,803$ & $13.7 \%$ & 2,460 & $11.0 \%$ & 77,602 & $8.9 \%$ & $3.4 \%$ & 1,061 & $14.6 \%$ & $43.1 \%$ \\
\hline Government & 146,018 & $0.9 \%$ & 190 & $0.8 \%$ & 19,060 & $2.2 \%$ & $13.1 \%$ & 38 & $0.5 \%$ & $20.0 \%$ \\
\hline Health & 78,117 & $0.5 \%$ & 302 & $1.3 \%$ & 4,386 & $0.5 \%$ & $5.6 \%$ & 82 & $1.1 \%$ & $27.2 \%$ \\
\hline Hobbies & 171,222 & $1.0 \%$ & 341 & $1.5 \%$ & 6,831 & $0.8 \%$ & $4.0 \%$ & 103 & $1.4 \%$ & $30.2 \%$ \\
\hline Lifestyle & 479,021 & $2.9 \%$ & 970 & $4.3 \%$ & 46,083 & $5.3 \%$ & $9.6 \%$ & 338 & $4.6 \%$ & $34.8 \%$ \\
\hline News/Information & 264,938 & $1.6 \%$ & 395 & $1.8 \%$ & 40,043 & $4.6 \%$ & $15.1 \%$ & 195 & $2.7 \%$ & $49.4 \%$ \\
\hline Portals & $3,607,436$ & $21.9 \%$ & 227 & $1.0 \%$ & 16,884 & $1.9 \%$ & $0.5 \%$ & 59 & $0.8 \%$ & $26.0 \%$ \\
\hline Real Estate & 71,982 & $0.4 \%$ & 67 & $0.3 \%$ & 2,728 & $0.3 \%$ & $3.8 \%$ & 15 & $0.2 \%$ & $22.4 \%$ \\
\hline Regional/Local & 72,081 & $0.4 \%$ & 230 & $1.0 \%$ & 26,426 & $3.0 \%$ & $36.7 \%$ & 122 & $1.7 \%$ & $53.0 \%$ \\
\hline Retail & 896,480 & $5.4 \%$ & 1,313 & $5.9 \%$ & 20,122 & $2.3 \%$ & $2.2 \%$ & 323 & $4.4 \%$ & $24.6 \%$ \\
\hline Search/Navigation & 409,879 & $2.5 \%$ & 197 & $0.9 \%$ & 17,107 & $2.0 \%$ & $4.2 \%$ & 61 & $0.8 \%$ & $31.0 \%$ \\
\hline Sports & 279,152 & $1.7 \%$ & 468 & $2.1 \%$ & 17,922 & $2.0 \%$ & $6.4 \%$ & 229 & $3.1 \%$ & $48.9 \%$ \\
\hline Technology & 152,928 & $0.9 \%$ & 280 & $1.2 \%$ & 2,942 & $0.3 \%$ & $1.9 \%$ & 105 & $1.4 \%$ & $37.5 \%$ \\
\hline Travel & 262,862 & $1.6 \%$ & 324 & $1.4 \%$ & 2,389 & $0.3 \%$ & $0.9 \%$ & 62 & $0.9 \%$ & $19.1 \%$ \\
\hline Services & $2,616,051$ & $15.9 \%$ & 2,489 & $11.1 \%$ & 145,265 & $16.6 \%$ & $5.6 \%$ & 733 & $10.1 \%$ & $29.4 \%$ \\
\hline Adult Content & $1,317,683$ & $8.0 \%$ & 5,154 & $23.0 \%$ & 106,362 & $12.2 \%$ & $8.1 \%$ & 1,642 & $22.6 \%$ & $31.9 \%$ \\
\hline Business to Business & 24,218 & $0.1 \%$ & 83 & $0.4 \%$ & 943 & $0.1 \%$ & $3.9 \%$ & 25 & $0.3 \%$ & $30.1 \%$ \\
\hline All Other & 406,822 & $2.5 \%$ & 2,764 & $12.3 \%$ & 100,180 & $11.4 \%$ & $24.6 \%$ & 772 & $10.6 \%$ & $27.9 \%$ \\
\hline Total & $16,496,314$ & $100.0 \%$ & 22,432 & $100.0 \%$ & 875,333 & $100.0 \%$ & $5.3 \%$ & 7,273 & $100.0 \%$ & $32.4 \%$ \\
\hline
\end{tabular}

Note: To be included in this table, a local site must have received at least 5,000 hits when scaled up to match the Internet-connected population. 
Table 3: Number of Large and Total Stores Nearby

\begin{tabular}{lcccccc}
\hline & \multicolumn{2}{c}{ books } & \multicolumn{2}{c}{ music } & \multicolumn{2}{c}{ clothing } \\
\hline within: & stores & $\begin{array}{c}\text { large stores } \\
(>\$ 1 \mathrm{M})\end{array}$ & stores & $\begin{array}{c}\text { large stores } \\
(>\$ 1 \mathrm{M})\end{array}$ & stores & $\begin{array}{c}\text { large stores } \\
(>\$ 1 \mathrm{M})\end{array}$ \\
\hline \hline 1 mile & 1.37 & 0.47 & 0.98 & 0.33 & 9.65 & 2.90 \\
2 miles & 3.59 & 1.29 & 2.55 & 0.87 & 26.15 & 8.18 \\
5 miles & 10.29 & 3.87 & 7.51 & 2.62 & 80.36 & 25.59 \\
10 miles & 27.26 & 10.41 & 20.34 & 7.11 & 224.57 & 71.62 \\
20 miles & 67.73 & 25.96 & 52.00 & 18.07 & 583.95 & 186.85 \\
& & & & & & \\
\hline
\end{tabular}

Note: $\mathrm{N}=18069$ 
Table 4: Average Number of Local Sites per Market, August 2000

\begin{tabular}{lccc} 
Category & Average & Minimum & Maximum \\
\hline Total Local Sites & 64.34 & 0 & 841 \\
Auctions & 0.21 & 0 & 5 \\
Automotive & 0.37 & 0 & 5 \\
Business/Finance & 1.08 & 0 & 21 \\
Careers & 0.43 & 0 & 8 \\
Community & 1.21 & 0 & 12 \\
Corporate Presence & 2.35 & 0 & 32 \\
Directories/Resources & 4.09 & 0 & 40 \\
Education & 1.82 & 0 & 21 \\
Entertainment & 9.36 & 0 & 121 \\
Government & 0.34 & 0 & 6 \\
Health & 0.73 & 0 & 8 \\
Hobbies & 0.91 & 0 & 11 \\
Lifestyle & 2.99 & 0 & 39 \\
News/Information & 1.73 & 0 & 29 \\
Portals & 0.52 & 0 & 8 \\
Real Estate & 0.13 & 0 & 3 \\
Regional/Local & 1.08 & 0 & 15 \\
Retail & 2.86 & 0 & 46 \\
Search/Navigation & 0.54 & 0 & 10 \\
Sports & 2.03 & 0 & 22 \\
Technology & 0.93 & 0 & 9 \\
Travel & 0.55 & 0 & 11 \\
Services & 6.49 & 0 & 79 \\
Adult Content & 14.53 & 0 & 191 \\
Business to Business & 0.22 & 0 & 7 \\
All Other & 6.83 & 0 & 95 \\
\hline & & &
\end{tabular}

Note: To be included in this table, a site must have received at least 5,000 hits when scaled up to match the Internet-connected population. 
Table 5: Local Sites and Market Size

\begin{tabular}{|c|c|c|c|c|c|c|c|c|c|c|c|}
\hline & $(1)$ & $(2)$ & (3) & (4) & $(5)$ & $(6)$ & (7) & $(8)$ & (9) & $(10)$ & $(11)$ \\
\hline & $\begin{array}{c}\text { Total Local } \\
\text { Sites, } \\
\text { Aug. } 2000 \\
\end{array}$ & $\begin{array}{l}\text { Directories/ } \\
\text { Resources } \\
\end{array}$ & Education & $\begin{array}{c}\text { Entertain- } \\
\text { ment }\end{array}$ & Lifestyle & $\begin{array}{c}\text { News/ } \\
\text { Information }\end{array}$ & $\begin{array}{l}\text { Regional/ } \\
\text { Local }\end{array}$ & Retail & Services & $\begin{array}{c}\text { Adult } \\
\text { Content }\end{array}$ & Misc \\
\hline Pop. '90 (mil.) & $\begin{array}{c}48.3976 \\
(0.6655)^{* *}\end{array}$ & $\begin{array}{c}2.6879 \\
(0.0867)^{* *}\end{array}$ & $\begin{array}{c}1.1084 \\
(0.0559)^{* * *}\end{array}$ & $\begin{array}{c}6.5455 \\
(0.1414)^{* *}\end{array}$ & $\begin{array}{c}2.0243 \\
(0.0878)^{* *}\end{array}$ & $\begin{array}{c}1.2532 \\
(0.0603)^{* *}\end{array}$ & $\begin{array}{c}0.7306 \\
(0.0459)^{* *}\end{array}$ & $\begin{array}{c}2.1823 \\
(0.0864)^{* *}\end{array}$ & $\begin{array}{c}5.0263 \\
(0.1045)^{* *}\end{array}$ & $\begin{array}{c}11.6647 \\
(0.2319)^{* * *}\end{array}$ & $\begin{array}{c}5.4720 \\
(0.1069)^{* * *}\end{array}$ \\
\hline Constant & $\begin{array}{l}-2.6580 \\
(1.8502)\end{array}$ & $\begin{array}{c}0.3678 \\
(0.2411)\end{array}$ & $\begin{array}{c}0.2888 \\
(0.1554)\end{array}$ & $\begin{array}{c}0.3022 \\
(0.3931)\end{array}$ & $\begin{array}{c}0.1890 \\
(0.2440)\end{array}$ & $\begin{array}{l}-0.0090 \\
(0.1676)\end{array}$ & $\begin{array}{c}0.0683 \\
(0.1276)\end{array}$ & $\begin{array}{l}-0.1625 \\
(0.2401)\end{array}$ & $\begin{array}{l}-0.4710 \\
(0.2905)\end{array}$ & $\begin{array}{c}-1.6159 \\
(0.6446)^{*}\end{array}$ & $\begin{array}{c}-0.7427 \\
(0.2971)^{*}\end{array}$ \\
\hline Observations & 113 & 113 & 113 & 113 & 113 & 113 & 113 & 113 & 113 & 113 & 113 \\
\hline R-squared & 0.98 & 0.90 & 0.78 & 0.95 & 0.83 & 0.80 & 0.70 & 0.85 & 0.95 & 0.96 & 0.96 \\
\hline
\end{tabular}

Notes: Standard errors in parentheses. $*$ significant at $5 \%$; ** significant at $1 \%$ 
Table 6: Does the Household Connection Tendency Depend on Market Size and Local Sites?

\begin{tabular}{|c|c|c|c|c|c|c|c|c|}
\hline & (1) & $(2)$ & (3) & (4) & $(5)$ & (6) & (7) & $(8)$ \\
\hline Log Pop & $\begin{array}{c}0.0089 \\
(0.0120)\end{array}$ & $\begin{array}{c}-0.1076 \\
(0.0353)^{* *}\end{array}$ & $\begin{array}{c}0.0061 \\
(0.0094)\end{array}$ & $\begin{array}{l}-0.0516 \\
(0.0350)\end{array}$ & & & & \\
\hline Log Local Sites & & $\begin{array}{c}0.1025 \\
(0.0297)^{* *}\end{array}$ & & $\begin{array}{c}0.0508 \\
(0.0305)\end{array}$ & & & & \\
\hline Pop (mil.) & & & & & $\begin{array}{l}-0.0008 \\
(0.0016)\end{array}$ & $\begin{array}{l}-0.0686 \\
(0.0350)\end{array}$ & $\begin{array}{c}0.0007 \\
(0.0013)\end{array}$ & $\begin{array}{l}-0.0147 \\
(0.0350)\end{array}$ \\
\hline Local Sites & & & & & & $\begin{array}{c}0.0015 \\
(0.0008)\end{array}$ & & $\begin{array}{c}0.0003 \\
(0.0008)\end{array}$ \\
\hline Constant & $\begin{array}{l}-0.2890 \\
(0.1744)\end{array}$ & $\begin{array}{c}0.9463 \\
(0.3924)^{*}\end{array}$ & $\begin{array}{c}-1.4707 \\
(0.3305)^{* *}\end{array}$ & $\begin{array}{c}-1.2091 \\
(0.4514)^{* *}\end{array}$ & $\begin{array}{c}-0.1534 \\
(0.0212)^{* *}\end{array}$ & $\begin{array}{c}-0.1719 \\
(0.0209)^{* *}\end{array}$ & $\begin{array}{c}-1.3836 \\
(0.2944)^{* *}\end{array}$ & $\begin{array}{c}-1.7423 \\
(0.2653) * *\end{array}$ \\
\hline $\begin{array}{l}\text { Controls } \\
\text { Observations }\end{array}$ & $\begin{array}{c}\text { No } \\
29027\end{array}$ & $\begin{array}{c}\text { No } \\
29027\end{array}$ & $\begin{array}{c}\text { Yes } \\
29027\end{array}$ & $\begin{array}{c}\text { Yes } \\
29027\end{array}$ & $\begin{array}{c}\text { No } \\
29027\end{array}$ & $\begin{array}{c}\text { No } \\
29027\end{array}$ & $\begin{array}{c}\text { Yes } \\
29027\end{array}$ & $\begin{array}{c}\text { Yes } \\
29027\end{array}$ \\
\hline
\end{tabular}

Notes: Probit estimates with household connection to the Internet (hesiu3) as the dependent variable. Robust standard errors in parentheses (clustered on MSA). * significant at 5\%; ** significant at 1\%. Controls include education of household head, presence of children, and household head age dummies. Households are the unit of observation. Data on local sites are calculated by the authors from Media Metrix data, and the remaining data are drawn from the August 2000 CPS Computer and Internet Use supplement. 
Table 7: Does Racial Isolation Explain Connection?

\begin{tabular}{|c|c|c|c|c|c|c|c|c|}
\hline & (1) & (2) & (3) & (4) & $(5)$ & (6) & (7) & $(8)$ \\
\hline & $\begin{array}{l}\text { Non- } \\
\text { Blacks }\end{array}$ & Black & & & $\begin{array}{l}\text { Non- } \\
\text { Blacks }\end{array}$ & Black & & \\
\hline Black Dummy & & & $\begin{array}{c}-0.6589 \\
(0.0316)^{* *}\end{array}$ & $\begin{array}{c}-0.1987 \\
(0.0084)^{* *}\end{array}$ & & & $\begin{array}{c}-0.5369 \\
(0.0655)^{* *}\end{array}$ & $\begin{array}{c}-0.1649 \\
(0.0167)^{* *}\end{array}$ \\
\hline Black Pop (mil) & $\begin{array}{c}0.0027 \\
(0.0317)\end{array}$ & $\begin{array}{l}-0.0602 \\
(0.0362)\end{array}$ & & & & & & \\
\hline Non-Black Pop (mil) & $\begin{array}{c}0.0013 \\
(0.0069)\end{array}$ & $\begin{array}{c}0.0221 \\
(0.0070)^{* *}\end{array}$ & & & & & & \\
\hline $\begin{array}{l}\text { Black Dummy x Black } \\
\text { Pop (mil) }\end{array}$ & & & $\begin{array}{c}-0.0972 \\
(0.0232)^{* *}\end{array}$ & $\begin{array}{c}-0.0294 \\
(0.0069)^{* *}\end{array}$ & & & & \\
\hline $\begin{array}{l}\text { Black Dummy x } \\
\text { Non-Black Pop (mil) }\end{array}$ & & & $\begin{array}{c}0.0276 \\
(0.0042)^{* *}\end{array}$ & $\begin{array}{c}0.0080 \\
(0.0012)^{* *}\end{array}$ & & & & \\
\hline MSA \% Black & & & & & $\begin{array}{l}-0.0474 \\
(0.1674)\end{array}$ & $\begin{array}{l}-0.5390 \\
(0.2893)\end{array}$ & & \\
\hline $\begin{array}{c}\text { Black Dummy x } \\
\text { MSA \% black }\end{array}$ & & & & & & & $\begin{array}{l}-0.4697 \\
(0.3068)\end{array}$ & $\begin{array}{l}-0.1363 \\
(0.0748)\end{array}$ \\
\hline Observations & $\begin{array}{l}25135 \\
\text { Probit }\end{array}$ & $\begin{array}{l}3892 \\
\text { Probit }\end{array}$ & $\begin{array}{c}29027 \\
\text { Probit } \\
\text { MSA FE }\end{array}$ & $\begin{array}{c}29027 \\
\text { LPM } \\
\text { MSA FE }\end{array}$ & $\begin{array}{l}25135 \\
\text { Probit }\end{array}$ & $\begin{array}{l}3892 \\
\text { Probit }\end{array}$ & $\begin{array}{c}29027 \\
\text { Probit } \\
\text { MSA FE }\end{array}$ & $\begin{array}{c}29027 \\
\text { LPM } \\
\text { MSA FE }\end{array}$ \\
\hline
\end{tabular}


Table 8: Online and Offline Spending by Merchandise Category and Distance to Nearest Stores

\begin{tabular}{lcccccccccc}
\hline & \multicolumn{3}{c}{ books } & \multicolumn{4}{c}{ music } & \multicolumn{4}{c}{ clothing } \\
\hline Distance & total & Internet/Catalog & Store & total & Internet/Catalog & Store & total & Internet/Catalog & Store \\
1 mile & $\$ 98.79$ & $\$ 45.16$ & $\$ 53.63$ & $\$ 93.19$ & $\$ 46.63$ & $\$ 46.55$ & $\$ 266.06$ & $\$ 93.40$ & $\$ 172.66$ \\
2 miles & $\$ 92.33$ & $\$ 45.48$ & $\$ 46.85$ & $\$ 84.92$ & $\$ 43.49$ & $\$ 41.42$ & $\$ 293.70$ & $\$ 119.19$ & $\$ 174.51$ \\
5 miles & $\$ 91.80$ & $\$ 46.04$ & $\$ 45.76$ & $\$ 85.90$ & $\$ 45.39$ & $\$ 40.51$ & $\$ 260.35$ & $\$ 92.27$ & $\$ 168.08$ \\
10 miles & $\$ 77.29$ & $\$ 37.56$ & $\$ 39.73$ & $\$ 78.11$ & $\$ 40.94$ & $\$ 37.17$ & $\$ 238.80$ & $\$ 85.33$ & $\$ 153.48$ \\
20 miles $\$ 70.20$ & $\$ 37.26$ & $\$ 32.94$ & $\$ 74.19$ & $\$ 41.67$ & $\$ 32.53$ & $\$ 238.07$ & $\$ 89.81$ & $\$ 148.26$ \\
Over 20 & $\$ 68.21$ & $\$ 35.83$ & $\$ 32.38$ & $\$ 75.49$ & $\$ 38.85$ & $\$ 36.64$ & $\$ 239.13$ & $\$ 90.92$ & $\$ 148.21$
\end{tabular}

\begin{tabular}{lcccccc} 
& \multicolumn{1}{c}{$\%$} & $\%$ & $\%$ & $\%$ & $\%$ & $\%$ \\
Distance & Internet/Catalog & Store & Internet/Catalog & Store & Internet/Catalog & Store \\
\hline 1 mile & $45.71 \%$ & $54.29 \%$ & $50.04 \%$ & $49.96 \%$ & $35.11 \%$ & $64.89 \%$ \\
2 miles & $49.25 \%$ & $50.75 \%$ & $51.22 \%$ & $48.78 \%$ & $40.58 \%$ & $59.42 \%$ \\
5 miles & $50.15 \%$ & $49.85 \%$ & $52.84 \%$ & $47.16 \%$ & $35.44 \%$ & $64.56 \%$ \\
10 miles & $48.59 \%$ & $51.41 \%$ & $52.42 \%$ & $47.58 \%$ & $35.73 \%$ & $64.27 \%$ \\
20 miles & $53.07 \%$ & $46.93 \%$ & $56.16 \%$ & $43.84 \%$ & $37.73 \%$ & $62.27 \%$ \\
Over 20 & $52.52 \%$ & $47.48 \%$ & $51.46 \%$ & $48.54 \%$ & $38.02 \%$ & $61.98 \%$ \\
\hline
\end{tabular}


Table 9: Regressions of Spending on Distance to Nearest Store

(1)

\begin{tabular}{|c|c|c|c|c|c|c|}
\hline $\begin{array}{l}\text { Coefficient on Miles to } \\
\text { Nearest Category Store }\end{array}$ & $\begin{array}{l}\text { Books } \\
\text { Internet or } \\
\text { catalog }\end{array}$ & Books offline & $\begin{array}{l}\text { Music } \\
\text { Internet or } \\
\text { catalog }\end{array}$ & Music offline & $\begin{array}{l}\text { Clothes } \\
\text { Internet or } \\
\text { catalog }\end{array}$ & Clothes offline \\
\hline No controls & $\begin{array}{c}-0.3851 \\
(0.0992)^{* *}\end{array}$ & $\begin{array}{c}-0.8723 \\
(0.0869) * *\end{array}$ & $\begin{array}{c}-0.2732 \\
(0.0945)^{* *}\end{array}$ & $\begin{array}{c}-0.4531 \\
(0.0719)^{* *}\end{array}$ & $\begin{array}{l}-0.2652 \\
(0.2722)\end{array}$ & $\begin{array}{c}-1.2459 \\
(0.2741)^{* *}\end{array}$ \\
\hline With controls & $\begin{array}{l}-0.2041 \\
(0.1107)\end{array}$ & $\begin{array}{c}-0.5461 \\
(0.0928)^{* *}\end{array}$ & $\begin{array}{c}-0.3216 \\
(0.1064)^{* *}\end{array}$ & $\begin{array}{c}-0.3579 \\
(0.0773)^{* *}\end{array}$ & $\begin{array}{l}-0.0485 \\
(0.3003)\end{array}$ & $\begin{array}{l}-0.4163 \\
(0.2845)\end{array}$ \\
\hline
\end{tabular}

Note: Controls include 17 household income dummies and 8 education dummies. 
Table 10: Spending and Distance to Nearest Store, FE Specifications

\begin{tabular}{lccc}
\hline & $(1)$ & $(2)$ & $(3)$ \\
\hline & Books & Music & Clothes \\
\hline Internet or Catalog Dummy & -4.4118 & 4.4705 & -74.2639 \\
& $(1.0043)^{* *}$ & $(0.9671)^{* *}$ & $(1.9536)^{* *}$ \\
Distance x Internet Dummy & 0.3379 & 0.0195 & 0.6755 \\
& $(0.1023)^{* *}$ & $(0.0856)$ & $(0.3152)^{*}$ \\
Constant & 47.1171 & 41.0772 & 167.6288 \\
& $(0.5895)^{* *}$ & $(0.5476)^{* *}$ & $(1.2100)^{* *}$ \\
Observations & 45115 & 45114 & 45113 \\
\hline
\end{tabular}

Notes: Standard errors in parentheses. * significant at 5\%; ** significant at $1 \%$. All specifications include individual fixed effects. 